\title{
Considerations in planning and implementing massive underground mines at depth
}

\author{
P.J. Bartlett South Africa
}

\begin{abstract}
Planning and implementing massive underground mines such as block caves at increasing depths is a process that can extend over many years and carries a considerable level of risk. This paper examines the time that it has taken some major underground mines to plan and implement new mines at depth and the implications of this extended process. Geotechnical concerns are a major source of uncertainty as mines move to greater depths. Gathering, interpreting and using the geotechnical data to plan and implement deep mines adds considerably to the time and uncertainty of the planning process.
\end{abstract}

\section{Introduction}

Where mines are implemented at increasing depth below existing mines by experienced personnel with knowledge of the orebody, the process of planning and implementing a new block cave can take as little as six years, unless there is a change in the mining method. Where mines are planned and implemented below open pits or at newly discovered sites the planning and implementation process can take decades (Stacey and Terbrugge, 2000). During this extended period of time, economic situations and personnel change, and mines can be bought and sold. New owners might have a different risk profile. Data gathering is often a continuous activity as subsequent project stages are undertaken and mine owners seek to minimise risk.

Geological data gathering, interpretation and application is well defined by codes that have been accepted in several mining countries. Methods of geotechnical data gathering are often more complex and not universally accepted. Laboratory testing is well defined by ISRM standards, but the quantity and quality of data that needs to be gathered is not defined by any generally accepted code. Stress measurements at depth are often problematic. Good and often pioneering work done by mining companies is not always as freely shared as previously for various reasons. Geotechnical data gathering and the use of geotechnical information to design deep mines can therefore add considerably to the time and uncertainty to the planning and implementation process.

Geotechnical standards need to be developed and applied as massive underground mining operations move to depths where generally accepted empirical design criteria are not always easy to use in mine design.

\section{New mines and projects}

New massive mining operations that are being planned at depth include the deepening of mines at El Teniente, Grasberg, Perseverance and Ridgeway, the development and extension of mines below deep open pits at Chuquicamata, Grasberg, Orapa, Jwaneng and Cadia East as well as new mines well in excess of $1,000 \mathrm{~m}$ depth that are in preliminary stages of planning at Resolution and Pebble mines.

All of these operations are major mines that will cost billions of dollars to bring into production and could have a marked effect on the supply of the commodities that they produce into the future. Failure of any of the projects could have an effect on the profitability of the companies that own and operate them.

\section{$3 \quad$ Planning and scheduling}

Resources, time and expertise are essential to the mine planning and scheduling process. Detailed resource information, both geological and geotechnical is essential. The need for detailed geological information is generally satisfied in accordance with the codes that pertain in countries such as Australia, Canada and South Africa. The detailed geotechnical information required for planning a mine at depth is often totally underestimated and results in project delays and an ongoing programme of data acquisition that makes final 
design difficult. In mines or companies such as Codelco, Henderson and Grasberg that are experienced in massive mining, the expertise to do conceptual and detailed planning is available. In new projects and where mining methods are changed, the expertise to do the conceptual planning is often not readily available.

It is essential that enough time and finances are allocated to undertake data collection - if required - as well as completing and implementing the planning. The choice of mining method must be based on a detailed assessment of the geotechnical characteristics of the orebody. There are numerous examples where orebodies have been sub-optimally mined simply because senior people in the company are familiar and comfortable with the mining methods that they use.

Methods of geological and geotechnical data collection generally used are drilling and various geophysical methods as these methods can be quick and relatively inexpensive. Early access shafts or declines are expensive, but are often essential to acquire the information required to plan and implement the mine. Where information is not available plans and models will be generated on the basis of interpretation, extrapolation and guesswork.

Once the data has been collected, it must be reviewed and a decision must be made as to whether the data is representative of the orebody. The more information available and the better the quality of the information the less extrapolation and guesswork are needed.

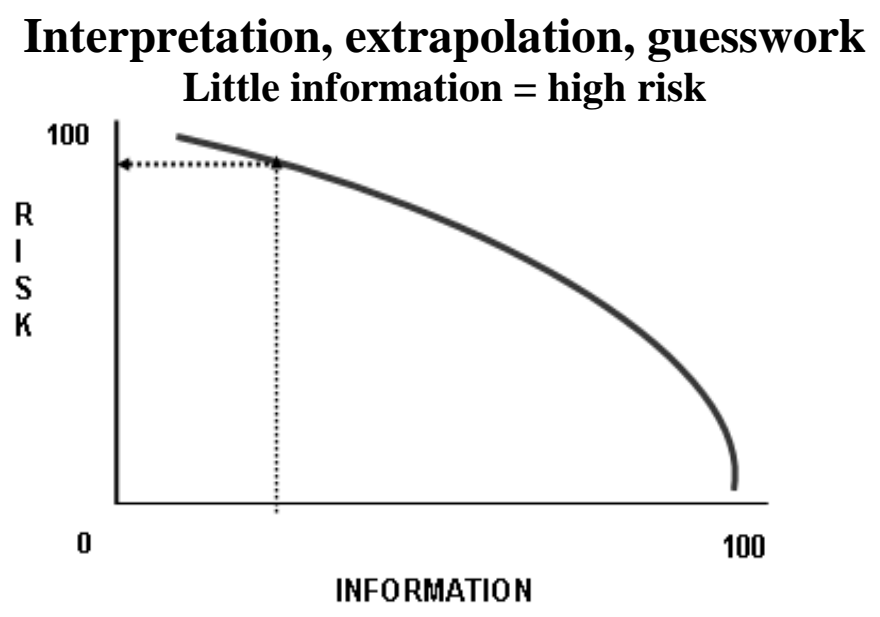

Figure 1 More information correlates with less risk

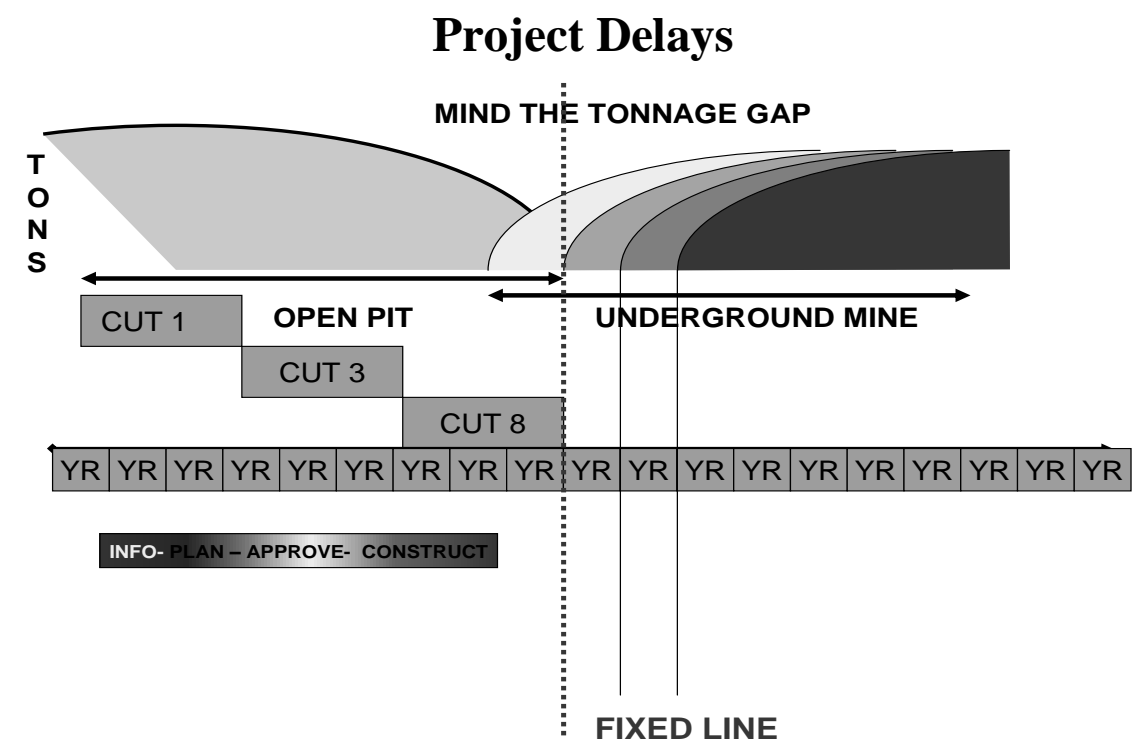

Figure 2 Some deadlines are fixed - delays result in lost revenue 


\section{Contributions from Underground}

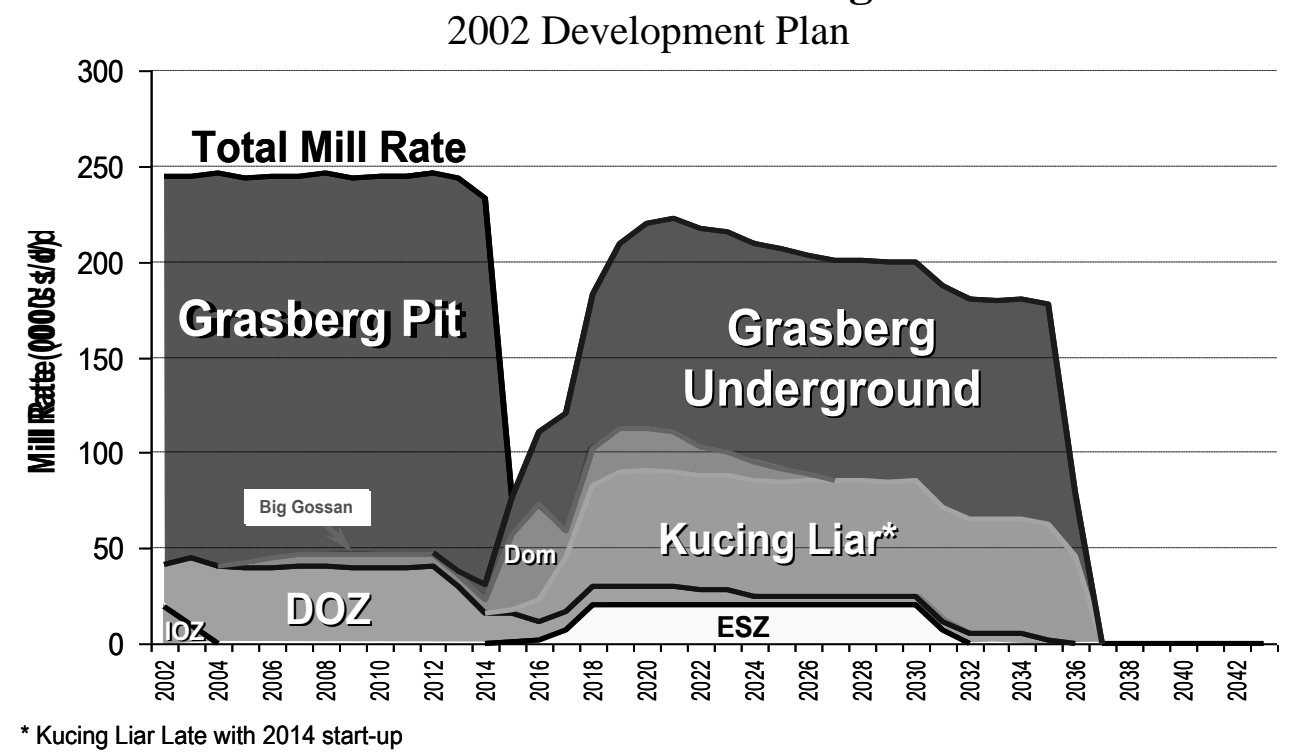

Figure 3 Delay in implementing the underground mine is usually expensive (Casten et al., 2008)

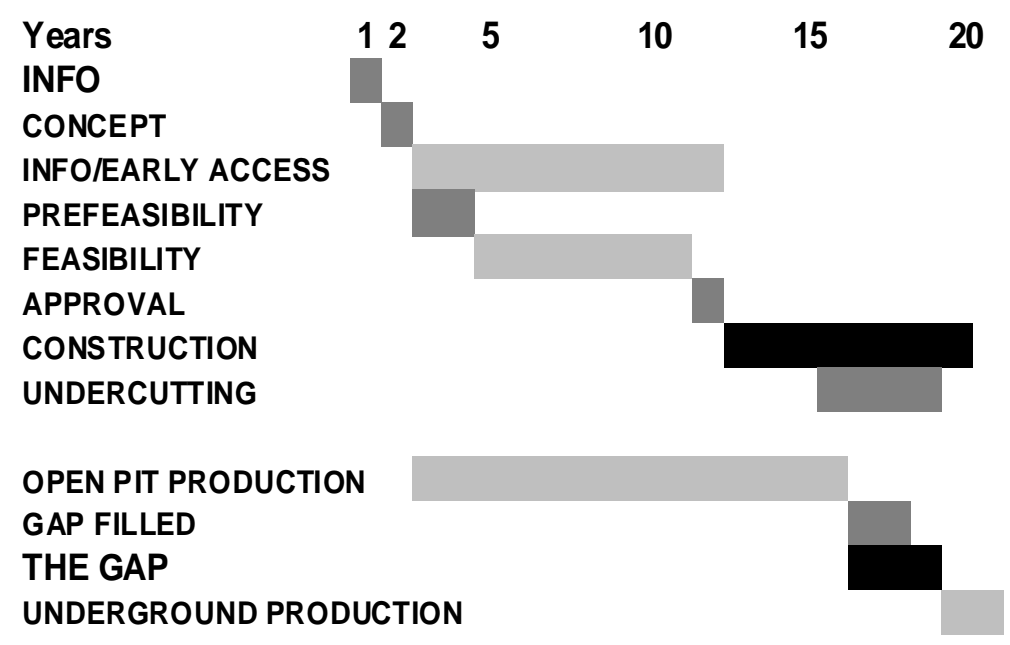

Figure 4 Palabora underground mine timeline

\subsection{Palabora project history}

An exploration shaft was sunk in the late 1980s to access the orebody at depth and provide geological and geotechnical information for a future underground mining operation. The project to develop the underground mine as a block cave with a production rate of 30,000 tpd and costing US\$ 450 million was approved in 1996. Undercutting started in December 1999 and was completed in January 2004. Drawbell blasting and all lateral development was completed in August 2004. The open pit continued to mine at the rate of 55,000 tpd until August 2002. Ramp scavenging to make up tonnage in the changeover period from open pit to underground continued until August 2004. Current production (2009) is at the rate of 34,000 tpd. 


\section{Mine A4 Project Schedule: Years}

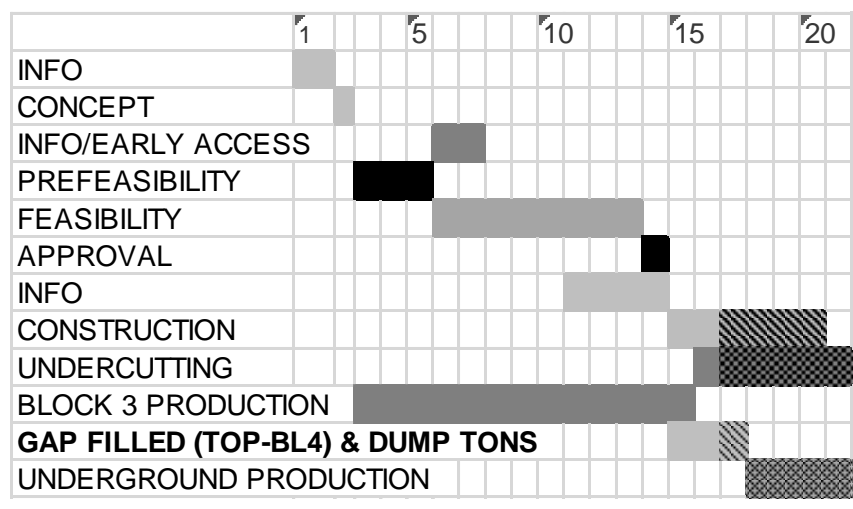

Figure 5 Planning and implementation timeline from another mine

\section{Geotechnical constraints on underground planning and implementation}

Geotechnical uncertainty is often a major factor in delaying the project. Data sufficient to inform a concept study usually proves insufficient to take the project into the selection stage if mine design criteria such as caveability, fragmentation and excavation stability are shown to be problematic. Sometimes the mine layout and infrastructure has already been expensively designed to a great level of detail, often to the level of a feasibility study on insufficient information. As possible geotechnical constraints are recognised, more data is required. The entire layout and infrastructure might need to be re-designed. Figure 6 sets out the logic of planning an underground block cave and suggests that fragmentation and caveability are the primary parameters that need to be assessed before further planning is done. As block caves progress to greater depths an assessment of excavation stability becomes equally important.

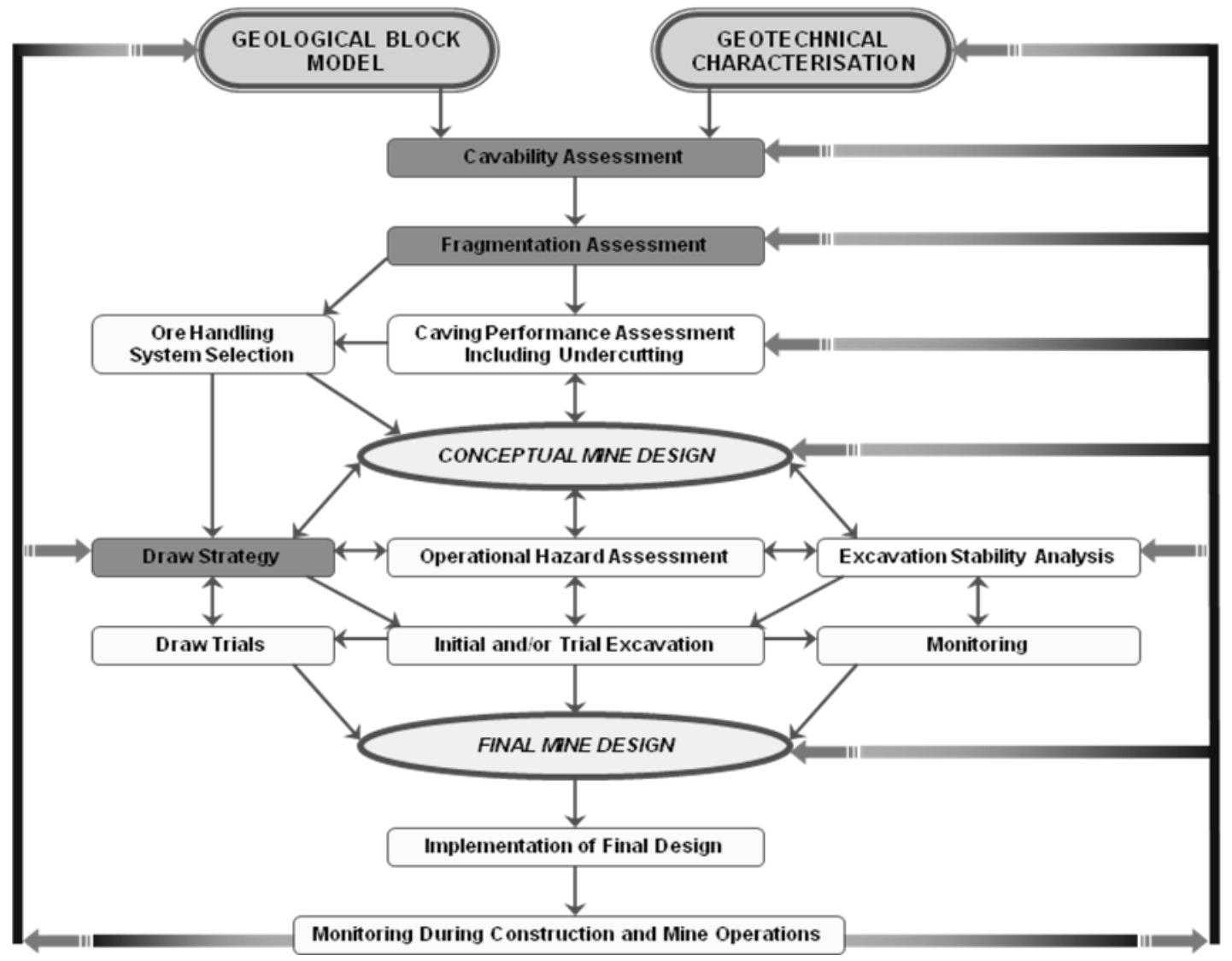

Figure 6 Planning and implementing a block cave mine (after Professor E.T. Brown, 2009, written comm.) 


\section{$5 \quad$ The impact of uncertainty on mine design parameters}

Empirical methods of planning and assessment largely based on Laubscher's (1995) work and experience has been effectively used by many major projects over the years. This has been augmented by the work of the International Caving Study.

As mines move to greater depths, however, empirical methods of cave design can become difficult to apply. Some typical problems are discussed.

Table 1 Geotechnical planning parameters (based on Professor E.T. Brown, 2009, written comm.)

\begin{tabular}{|c|c|c|c|c|}
\hline Parameter & $\begin{array}{l}\text { Method of } \\
\text { Assessment } \\
\text { Commonly Used }\end{array}$ & Effectiveness & $\begin{array}{l}\text { Subjective \% } \\
\text { Uncertainty }\end{array}$ & $\begin{array}{l}\text { Other Methods of } \\
\text { Assessment Used }\end{array}$ \\
\hline Caveability & $\begin{array}{l}\text { Laubscher's } \\
(1995) \text { empirical } \\
\text { graph }\end{array}$ & $\begin{array}{l}\text { Widely used. } \\
\text { Difficult to apply in } \\
\text { complex geology. }\end{array}$ & $20 \%$ & $\begin{array}{l}\text { Matthew's stability } \\
\text { graph, numerical } \\
\text { modelling }\end{array}$ \\
\hline Fragmentation & BCF software & $\begin{array}{l}\text { Widely used. } \\
\text { Need accurate data. } \\
\text { Little data available for } \\
\text { back analysis. }\end{array}$ & $15 \%$ & $\begin{array}{l}\text { Various other } \\
\text { methods }\end{array}$ \\
\hline $\begin{array}{l}\text { Excavation } \\
\text { Stability } \\
\text { Analysis }\end{array}$ & $\begin{array}{l}\text { Numerical } \\
\text { modelling }\end{array}$ & $\begin{array}{l}\text { Only available method. } \\
\text { Can be subjective. }\end{array}$ & $20 \%$ & \\
\hline $\begin{array}{l}\text { Support } \\
\text { System }\end{array}$ & Experience & $\begin{array}{l}\text { Often results in under- } \\
\text { support and rehabilitation. }\end{array}$ & $50 \%$ & $\begin{array}{l}\text { Numerical } \\
\text { modelling }\end{array}$ \\
\hline Draw Control & PCBC software & $\begin{array}{l}\text { Widely used. } \\
\text { Effective planning tool. }\end{array}$ & $20 \%$ & Rebop, MILP \\
\hline
\end{tabular}

\subsection{Caveability}

Caveability assessment is most often based on Laubscher's (1995) empirical graph, but is increasingly difficult to apply in deep mines with high stress and complex geology. Problems arise, however, when caving occurs at a greater (or lesser) hydraulic radius than expected. Figure 7 shows the considerable range in predicted hydraulic radius assessed at Palabora.

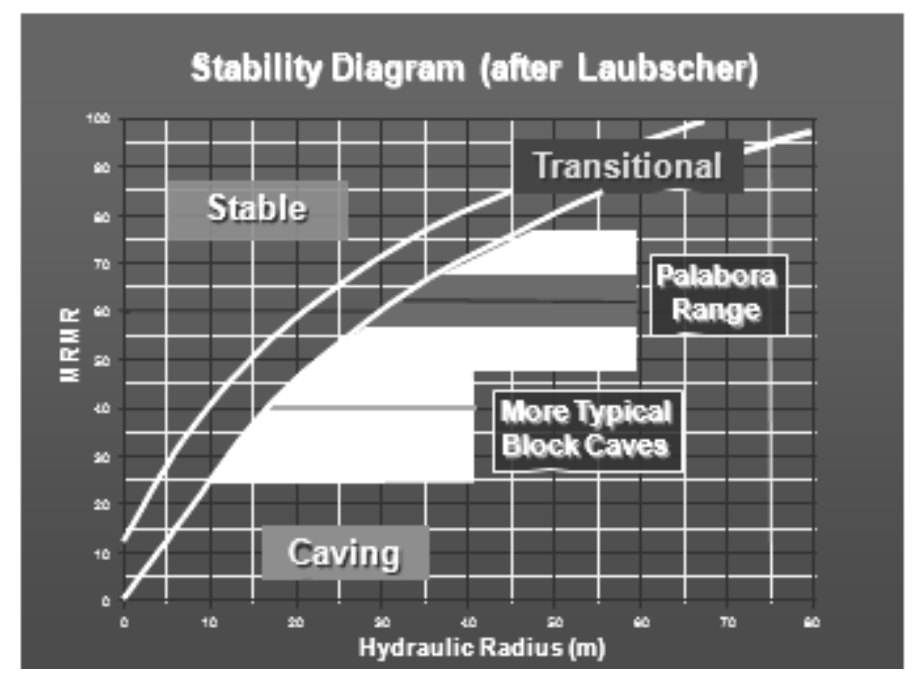

Figure 7 Caving at Palabora initiated at a larger hydraulic radius than anticipated (Calder et al., 2000) 
Failure to cave at the predicted hydraulic radius or failure to propagate usually curtails production as additional undercut tunnels and drawbells must be developed. Swell factors are uncertain and can change as the cave propagates; an air gap can form; these problems have been addressed in detail by Codelco personnel at Chuquicamata.

\subsection{Fragmentation}

Fragmentation assessment is often based on BCF software, an expert programme compiled by Laubscher and Esterhuizen in 1986 using Premier Mine data. The program has subsequently been considerably improved, as experience has shown that good data is required to use the program effectively. Geotechnical data that might be sufficient to plan other aspects of the mine might not be sufficient to predict fragmentation. The result is that actual fragmentation is often finer than expected.

Problems arise when fragmentation is not as predicted. In most caves initial fragmentation is coarse as large rocks fall under the influence of gravity from the cave back and report to drawpoints with limited distance of travel and time for comminution in the draw column. Fragmentation becomes finer as the cave propagates. In the final stages cushioning can result in coarse rocks reporting at the end of the cave. Rock mass parameters can obviously impact on expected fragmentation. Widely spaced jointing results in coarse fragmentation and causes more hang-ups which often require more drilling and blasting resources than are immediately available. Finer-than-expected fragmentation means that expensive drilling, blasting and crushing resources might never be required. In extreme situations very fine fragmentation can result in mud pushes, rushes and 'dust runs'.

\subsection{Stability of excavations}

Experience in designing block caves at depth has shown that it is important to establish the stability of excavations, especially where stress levels are uncertain in magnitude and direction and rock mass strengths are variable and not well defined. This needs to happen before a block cave can be planned, even at the conceptual level.

- Post, advance and pre-undercut mining sequences can be implemented to minimise the extraction ratio on the production level so that extraction level excavations and pillars are not subjected to high and changing abutment stress as the undercut face moves overhead. The mining sequence can protect the production level but the undercut level becomes problematic. Empirical failure criteria, especially where stress levels and k ratios are high, carry considerable uncertainty. Support design under conditions of uncertainty can be difficult.

- The effect of developing the extraction level can be damaging, even when an advance undercut mining sequence has been used to protect the rock on this level from abutment stresses. Confinement is removed from the pillars formed on the extraction level and levels of plastic strain can be considerably higher than anticipated. Areas of the cave can 'sit down' and/or continuous rehabilitation of the level is required soon after the cave comes into production and cave loads are imposed. Possible implications need to be carefully assessed as this obviously impacts on production costs.

- Aspects that relate to stress and rock mass strength parameters are not easy to define or assess empirically.

- Empirical methods related to rock mass classification do not have rock mass failure criteria. Hoek-Brown and/or Mohr-Coulomb criteria are generally used.

\section{Some solutions}

El Teniente, with a long history of cave mining, has recognised most of these problems in their mining operations and has proposed some practical solutions (Areneda and Sougarret, 2008):

- reduced width caving faces - this allows better control and reduces stress

- block type mining sequence 
- massive preconditioning

- advance undercut

- under level design to create more robust pillars between undercut tunnels.

Numerical modelling is being increasingly used as a planning and assessment tool. Numerical modelling was used extensively to assess the need for implementing an advance undercut in the BB1E mining block at Premier Mine. Figure 8 shows predicted stress related damage on the extraction level as the undercut advances over the area. Figure 9 shows predicted levels of stress damage in more detail as the abutment stresses approach.

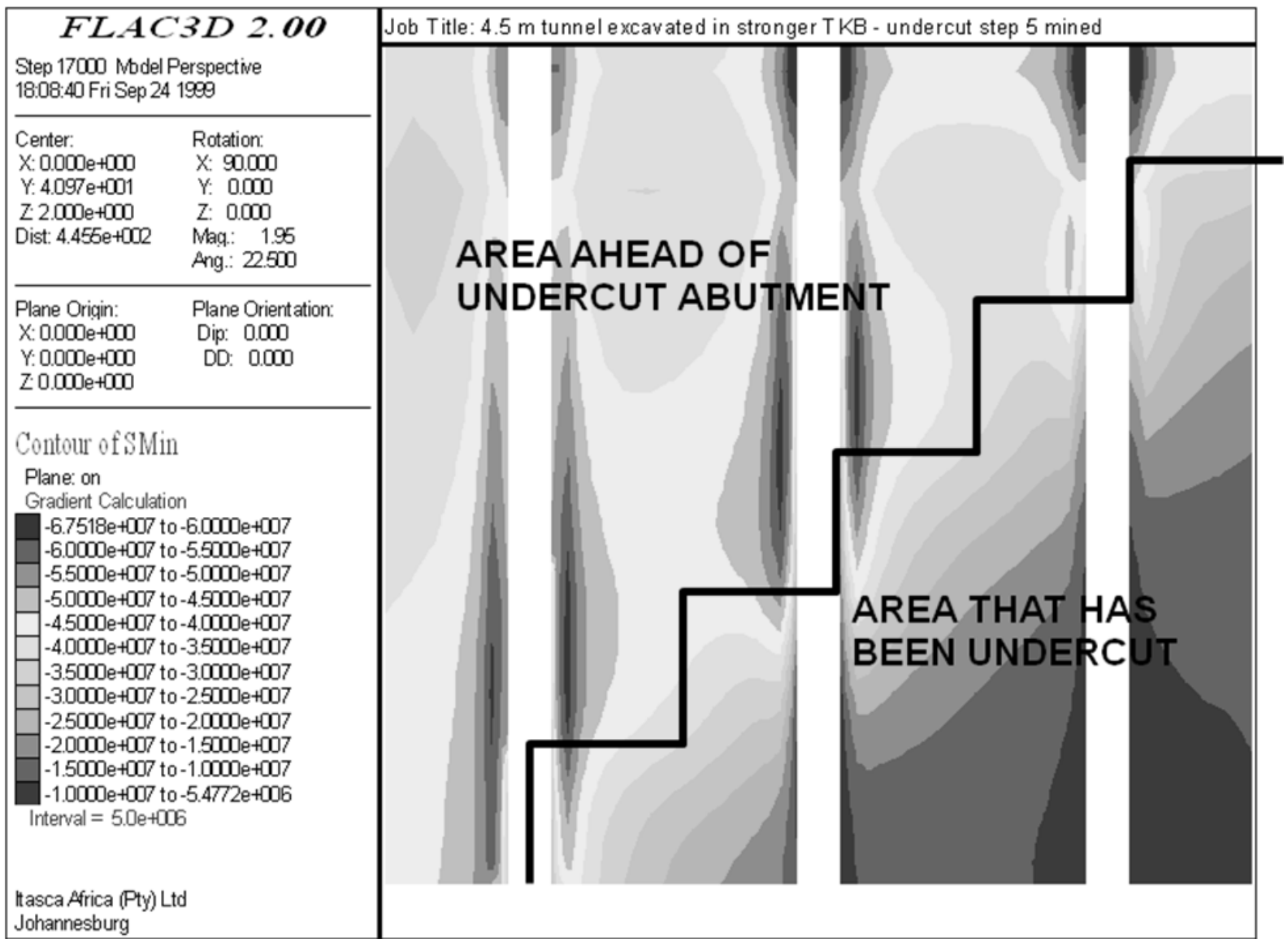

Figure 8 Predicted damage on extraction level as undercut passes overhead 

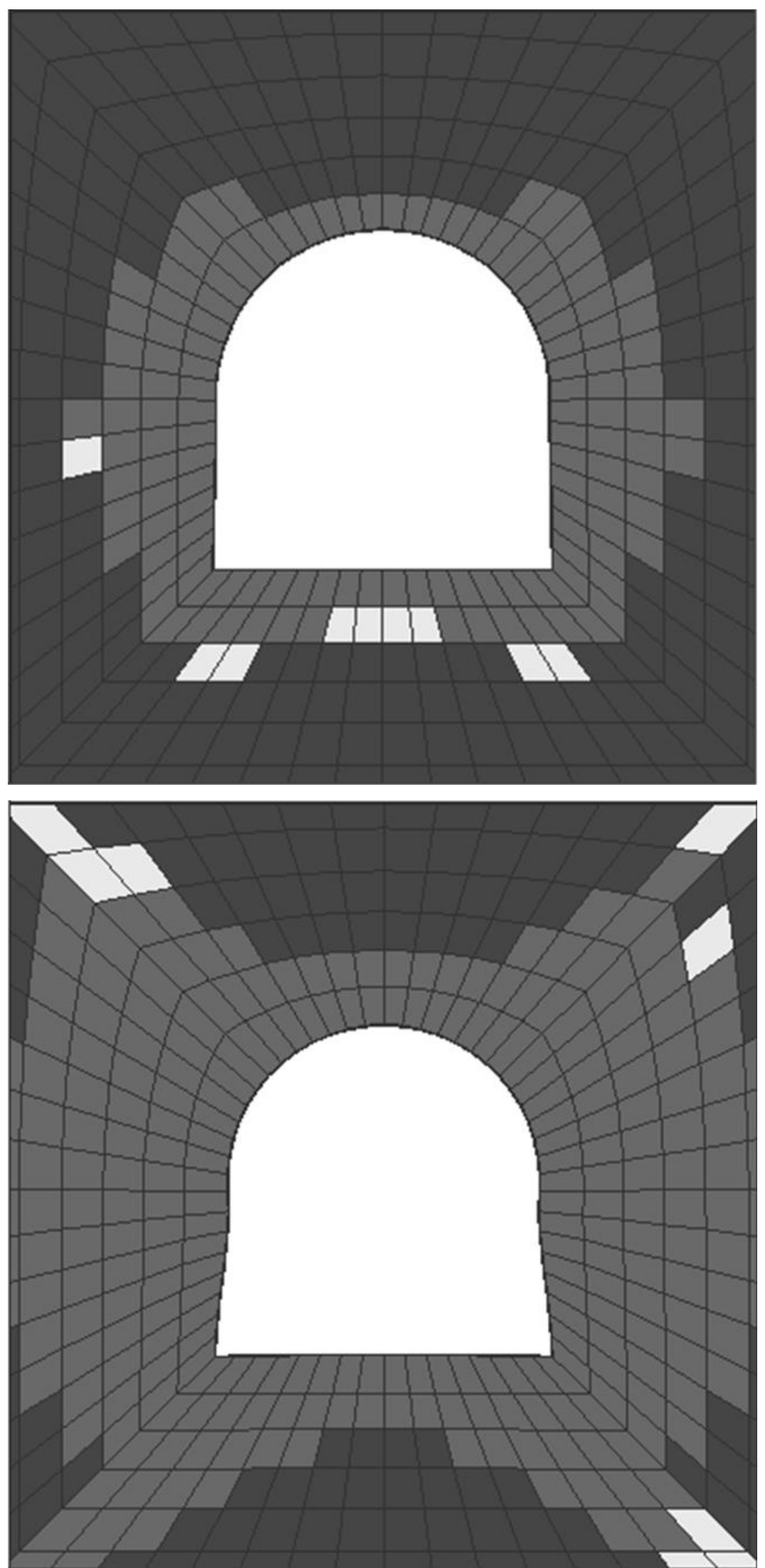

Figure 9 Stress related damage as extraction level tunnels are affected by advancing abutment stresses - (top) shows damage $15 \mathrm{~m}$ ahead of the undercut abutment stresses; (bottom) shows damage $5 \mathrm{~m}$ ahead of the abutment stress

Stress related problems at Premier Mine on the extraction level where a block cave was developed at $732 \mathrm{~m}$ depth in weak rock (unconfined compressive strength 40-60 MPa, mining rock mass rating 25-45) were addressed by developing a pre-undercut which ensured that extraction level excavations and pillars were never subjected to abutment stress. As the undercut increased in size, however, stresses on the undercut level 
resulted in collapse of pillar cores between the undercut tunnels which were spaced $12 \mathrm{~m}$ apart. Several kilometres of undercut tunnel were lost.

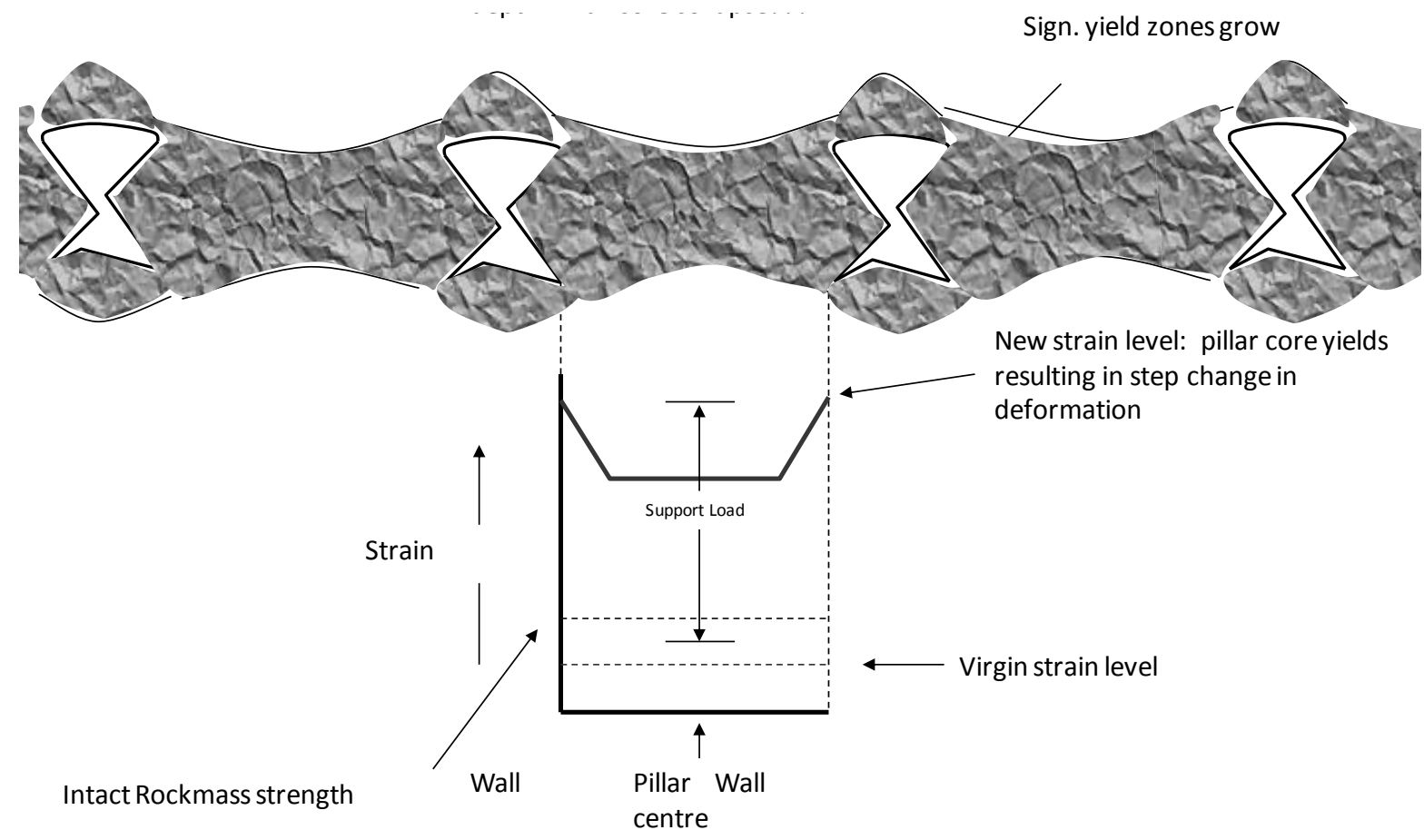

Figure 10 Back analysis showing that pillar cores between undercut levels have collapsed (Beck Arndt, 2005)
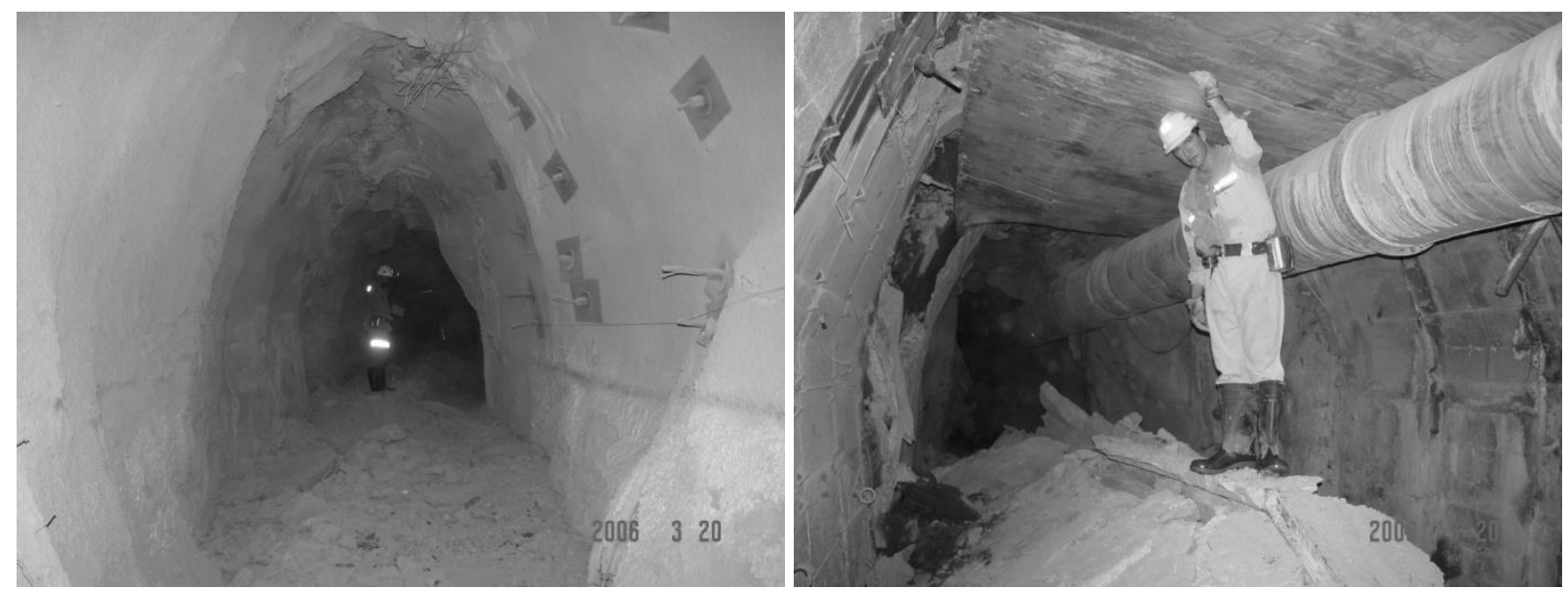

Figure 11 Actual tunnel convergence and footwall heave experienced underground

Back analysis was undertaken to explain and understand the extensive undercut tunnel collapse that occurred in the AUC mining block at Premier Mine. Modelling, the results of which are depicted in Figure 10, showed that the pillars between the undercut tunnels had collapsed and allowed the tunnel damage as seen in Figure 11 to be predicted.

Figures 12 and 13 show how a proposed support system can be modelled to predict how elements of the system will behave as the rock mass experiences various levels of plastic strain. 


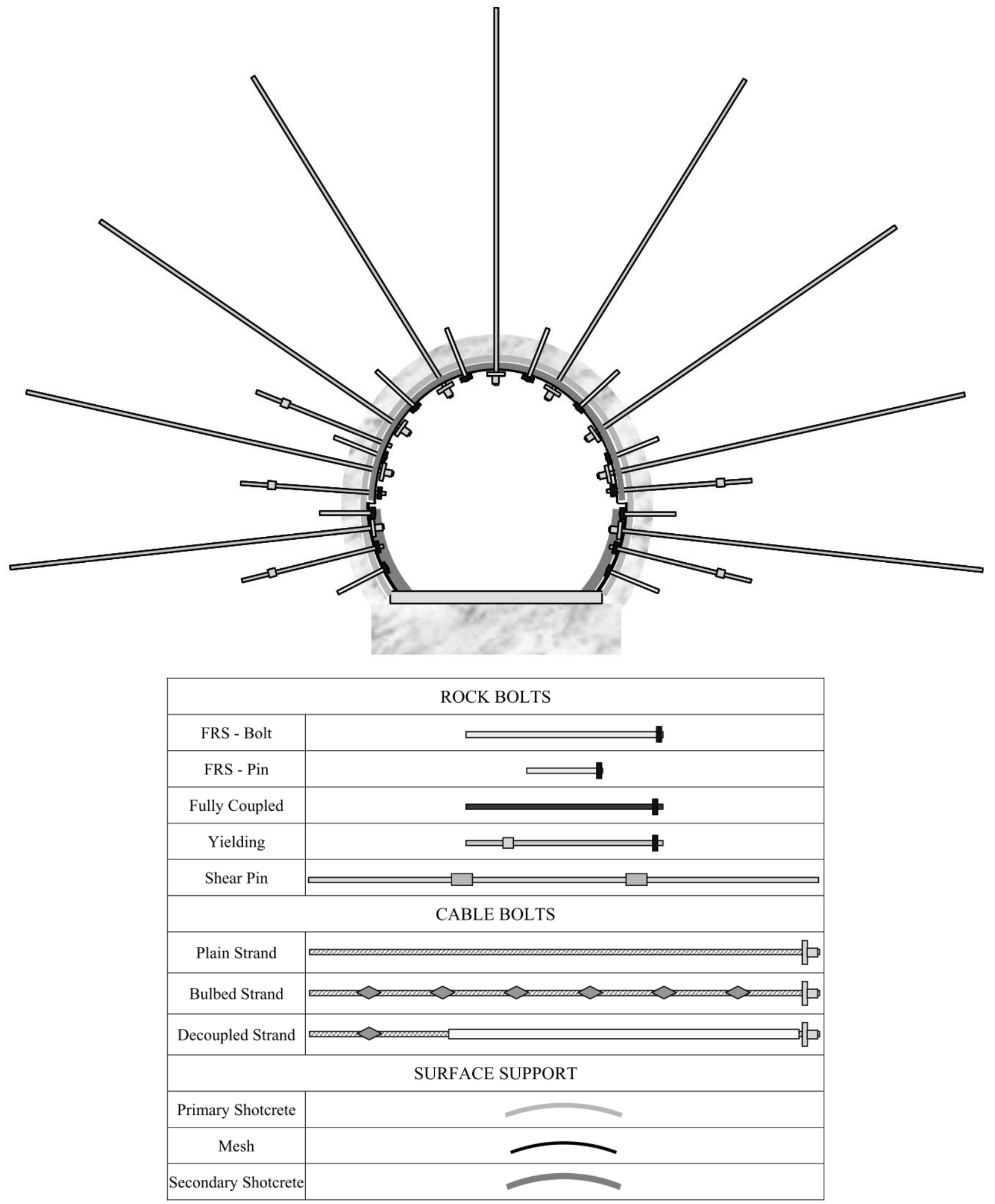

Figure 12 Proposed support system (after Windsor, 2007) 

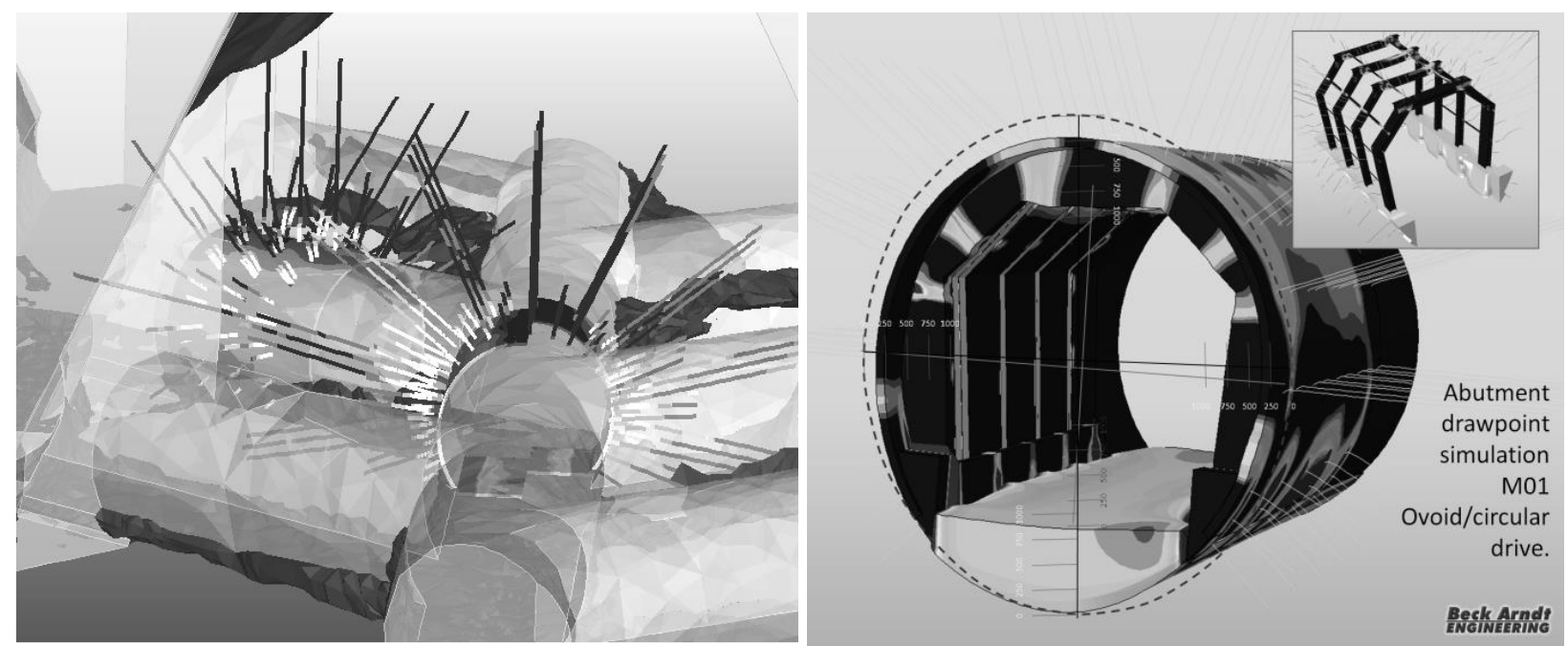

Figure 13 Assessment of support systems (after Beck Arndt, 2005)

Seismicity and mining related subsidence can be predicted and alternate mining layouts assessed using increasingly sophisticated numerical modelling.

\section{Conclusions}

Planning and implementing a massive underground mine is a complex process. Where the mine or operating company is familiar with the mining method and geological and geotechnical information is available, the process can take as little as six years. Where a new mine is being designed and little information is available the process can take as long as 20 years. Typically, 20 years is longer than a normal commodity cycle and the decision to mine can be further delayed by financial uncertainty. Twenty years is also longer than the period that most technical people stay on one mine or with one company and continuity can be lost. New employees might decide to restart the process.

Data acquisition methods and processes are well defined by ISRM. Data requirements to design a mine are, however, usually less well defined. The level of data required to inform a concept study are less onerous than for a feasibility study. This often leads to a process of re-iterative geotechnical data gathering. Additional data can result in a complete revision of the geotechnical model resulting in major concept changes as the implications of the new data set becomes clear. Methods of data assessment are not always agreed and can lead to uncertainty in the mine design process. The time taken to gather the data and, if necessary, replan aspects of the mine is seldom factored into project scheduling.

Mining companies and geotechnical engineers need to develop better and agreed methods to address the extended time that it can take to design, plan and implement a modern, massive, underground mine at depth. Geotechnical aspects often form a major part of the time delay and uncertainty.

\section{References}

Areneda, O. and Sougarret, A. (2008) Lessons learned in cave mining at the El Teniente mine over the period 19972007, in Proceedings MassMin 2008, 5th International Conference and Exhibition on Mass Mining, Luleå, Sweden, 9-11 June.

Beck Arndt (2005) GS2006DEC25, DeBeers Premier Undercut Collapse, unpublished report, Beck Arndt Engineering.

Calder, K., Townsend, P. and Russell, F. (2000) The Palabora Underground Mine Project, in Proceedings MassMin 2000, Brisbane, Australia, 29 October to 2 November.

Casten, T., Rachmad, L., Arkadius, T., Osborne, K. and Johnson, M. (2008) PT Freeport Indonesia's Deep Ore Zone mine - expanding to 80,000 tonnes per day, in Proceedings MassMin 2008 5th International Conference and Exhibition on Mass Mining, Luleå, Sweden, 9-11 June.

Laubscher, D.H. (1995) Cave Mining - The State of the Art, Journal of the South African Institute of Mining and Metallurgy, Vol. 94, No. 10. 
Stacey, T.R. and Terbrugge, P.J. (2000) Open Pit to Underground - Transition and Interaction, in Proceedings MassMin 2000, Brisbane, Australia, 29 October to 2 November.

Windsor, C.R. (2007) WA School of Mines, PD Project Report, unpublished. 